Special issue of the International Conference on Computational and Experimental Science and Engineering (ICCESEN 2014)

\title{
Design of Wave Energy Converter System with Linear Generator
}

\author{
M.E. ŞAHIN* AND I. ÖZDINÇ \\ Recep Tayyip Erdogan University/Department of Physics, Rize, Turkey
}

\begin{abstract}
It is not wrong to say that wave energy will be one of the most important energy sources to be used in the future, when it is thought that three-quarters of the world is covered by water. The initial investment and maintenance costs are the only expenses, beside not any price have to be paid for the primary energy. The wave energy does not leave any contaminants, as well as it is cheap, clean, environmentally, friendly and a great energy sources. In this study, wave energy converter system which has a four poles linear generator is discussed. The Linear generator model has been designed and created as a portable model. The results obtained from this model were examined.
\end{abstract}

DOI: 10.12693/APhysPolA.128.B-243

PACS: 88.60.nf, 07.10.-h

\section{Introduction}

Wave energy is one of the renewable energy technologies. It is not only big energy source, but also it is more reliable than other renewable energy sources. While sun and wind energy can be obtained in $20-30 \%$ of the time, wave power can be obtained in $90 \%$ of the time [1]. The power of the wave is proportional to the square of the amplitude and period of the movement. Waves, which has long-period $(7-10 \mathrm{~s})$ and large amplitude $(\approx 2 \mathrm{~m})$, consists of $40-50 \mathrm{~kW}$ energy [2]. Like other renewable energy sources, wave energy does not have a regular distribution in the world. This situation needs innovative applications in the design of wave energy converters $[3,4]$.

Some different studies about ocean wave energy technique and economy have been introduced. It will be an economical method for energy source solution in the future $[5,6]$. Some of different studies are realized about linear wave energy converters [7]. A model is simulated for octagonal linear wave generator [8]. A similar system is used for different application [9].

In this study, wave energy converter system with fourpole linear generator is discussed. Theoretical principles that are used in the design of the linear generator system are provided. Also quadruple linear generator has been designed as a portable model and it has been created. The results obtained for this model has been experimentally investigated.

\section{Components of linear generator and its design}

In general, generators are based on the principle of inducing electrical tension on the wire that moves in a magnetic field with the action of a mechanical force as shown in Fig. 1 (top). Generators consist of two main

*corresponding author; e-mail: mustafaerginsahin@yahoo.com parts, one of them is called as stator and the other one is called as rotor. In general, the moving part is called as rotor; fixed part is called as stator. There is an air gap between stator and rotor, because the rotor can be moved. A linear generator models is shown in Fig. 1 (bottom).

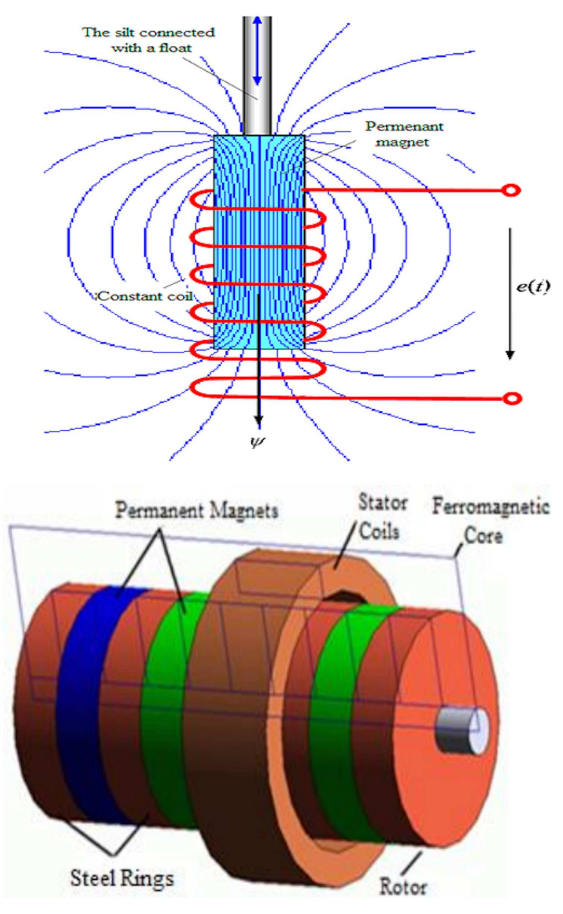

Fig. 1. Linear generator schemes that having a permanent magnet rotor.

The moving part of the linear generator in which the rotor consists of four fixed ring magnet is in the designed system. The magnets which are used for rotors, are Neodymium-Iron magnets, is the value of each 3000 Tesla. Non-magnetic permeability steel rings are placed between the permanent magnet and their poles are placed as N-S and S-N as shown in Fig. 2 (top) and 

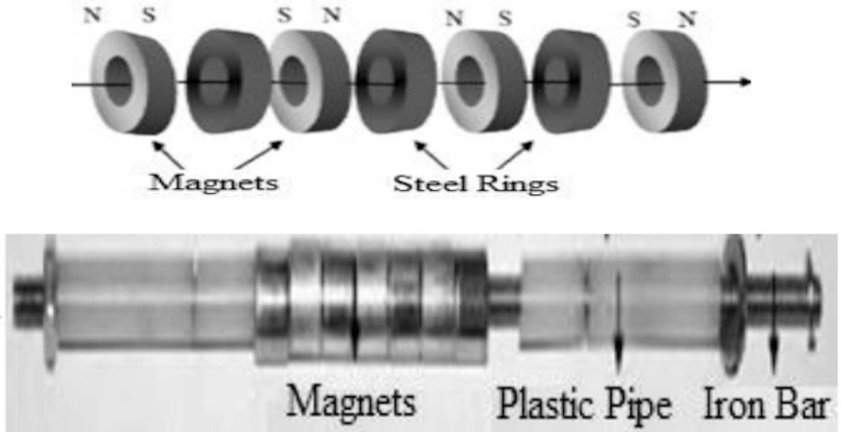

Fig. 2. (top) The placing of the magnets according to the poles, (bottom) appearance of the rotor constructed.

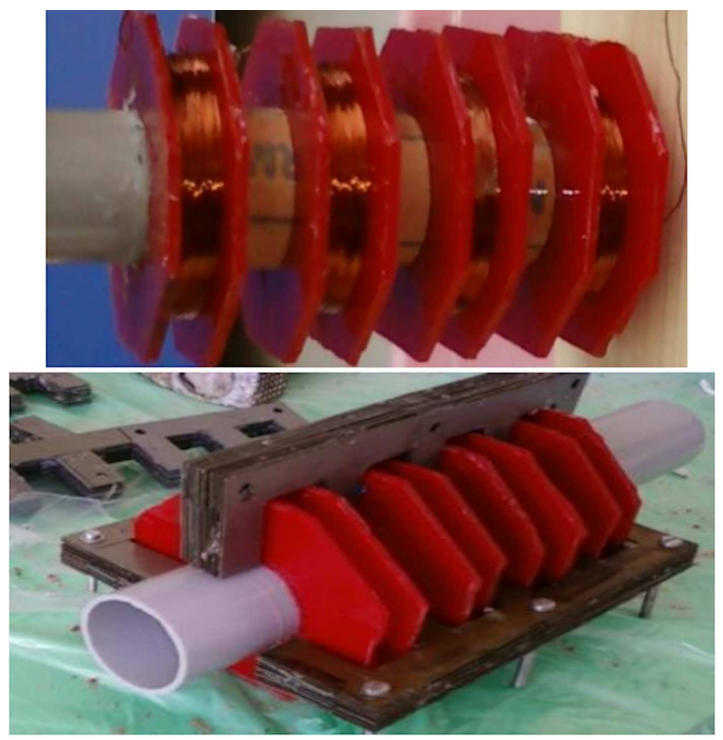

Fig. 3. (top) The first design of the designed four-pole linear stator, (bottom) second version after adding iron core.

the magnets are fixed by compression with a worm gear. The structure of the rotor appears in Fig. 2 (bottom).

Generally stator is the fixed part which includes windings and located in the outer part of the linear generator. To design the stator, the number of turns was calculated according to the desired voltage values and the desired number of poles. After this stage, octagonalshaped pulleys which will wound into the stator windings and iron cores that will be installed in it were cut. 8 pieces of octagonal were cut for 4 -pole winding. Iron cores are fixed on the $3 \mathrm{~cm}$ diameter-plastic pipe. The $0.45 \mathrm{~mm}$ diameter-copper wire that is enamelled was used for winding and 600 winds are wounded for each pole. The consisting stator is shown in Fig. 3 (top). Then, E-shaped iron sheets were cut in the desired size for the design of the stator and attached to each other. Later, insulated E-shaped cores were placed on top of the octagonal pulleys in $45^{\circ}$ between each other.
The appearance of the stator that was constructed is shown in Fig. 3 (bottom).

\section{The experimental study}

At this stage the stator parameters were found by forming stator's equivalent circuit. While the windings are connected in series, the equivalent circuit is as in Fig. 4 (top). Inductance values of the coils for each pole and the equivalent series resistances were found by measuring. The phase diagram of equivalent circuit is shown in Fig. 4 (bottom).

After this stage, the mechanism in Fig. 5 (top) is performed to ensure smooth linear motion and to secure mechanism. The linear generator wave energy system that can be used as a lighthouse. The Solid works software plotted system shown in Fig. 5 (bottom) from different angles.

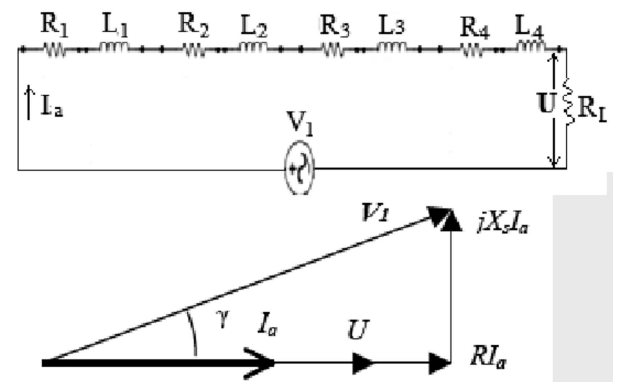

Fig. 4. The equivalent circuit of the stator and phase diagram.
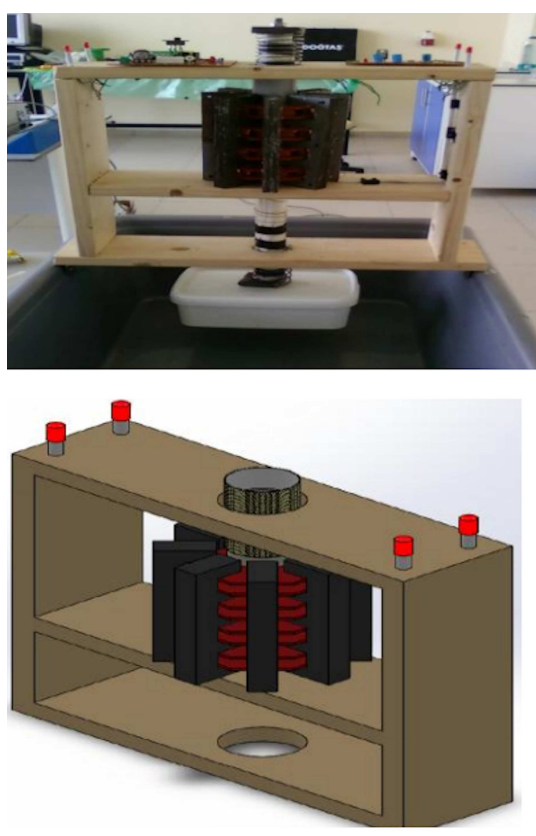

Fig. 5. (top) Designed wave energy converter system, (bottom) 3D modelling of the system in Solid works. 


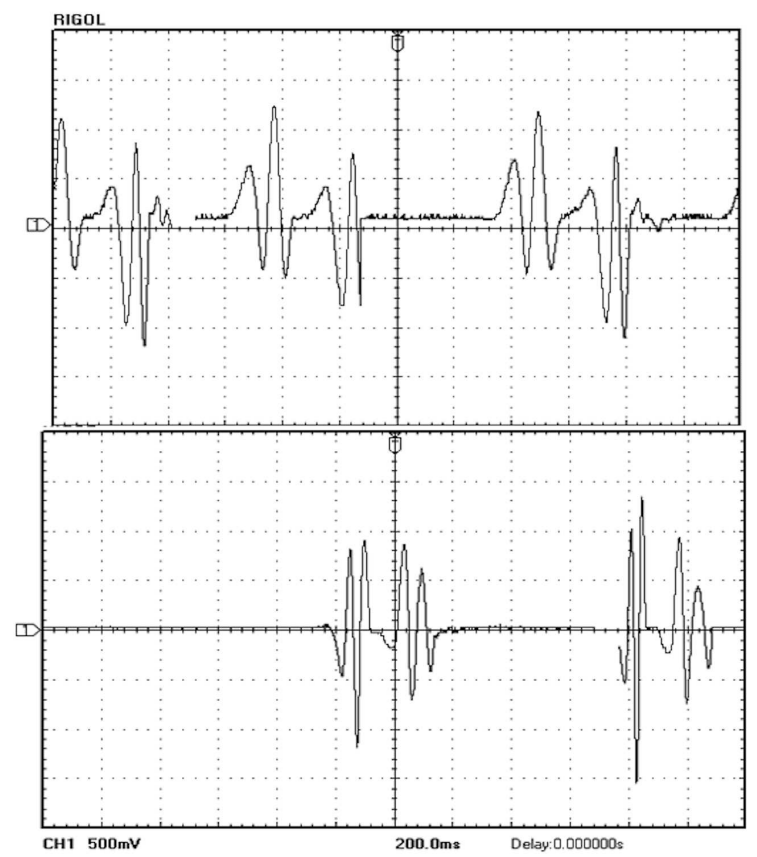

Fig. 6. Voltage measurement results; (top) without iron core, (bottom) with iron core.

At last measurements are taken at oscilloscope without the iron core and wave period is set to about 1 second. For each period of wave, the peak to peak voltage value is measured maximum $800 \mathrm{mV}$ as shown in Fig. 6 (top). During a period of one second wave consists of four different AC signals for four-poles. Then the necessary iron cores were added to prevent losses of magnetic flux on stator and measurements were repeated. After iron cores were added on a generator system, measurements which were repeated showed a significant increase on the voltage value. The voltage up to $3 \mathrm{~V}$ was observed as shown in Fig. 6 (bottom).

The obtained signal is alternate and of irregular shape, must be first rectified and then amplified desired value. For this, additional circuits are required. The obtained voltage is rectified with a simple rectifier circuit to turn on the LEDs.

\section{Conclusions}

In this study design of a linear motion generator for wave power was realized. In this context, the four pole linear generator which is made of special magnets was designed. The iron cores required for flux are observed to increase the efficiency.

For a good design, the length of the rotor should be equal to the length of the winding field in the stator. Therefore, this area is the maximum variation of magnetic flux. A mechanism is required which reduces friction losses between rotor and stator with a minimum air gap. The mechanism has to be fixed to the rotor to move only vertical direction with wave motion. The bigger conductor cross section reduces the power losses. It is noted that the obtained voltage value can be increased with the addition of power electronic circuits and more smooth DC voltage can be obtained.

\section{References}

[1] R. Pelc, R.M. Fujite, Mar. Policy 26, 471 (2002).

[2] Wave Energy Utilization in Europe: Current Status and Perspectives, Centre for Renewable Energy Sources, CRES, Pikermi 2003.

[3] M.E. Şahin, H.İ. Okumuş, A.S. Akpınar, Dalga Enerjisi ve Deniz Dalgalarından Elektrik Enerjisi Üretim Yöntemleri, Faal Enerji Journal, Mayıs-Haziran, 2011.

[4] M. Mehrübeoğlu, L. McLauchlan, IEEE Green Technology Conference, 2009.

[5] J. Cruz, Ocean Wave Energy; Current Status and Future Perspectives, Springer Press, UK 2008.

[6] T.W. Thorpe, Wave Power, IMECHE Seminar, London, 50-120, 1999.

[7] O. Danielsson, M. Th., Engineering Physics Programme at Uppsala University, Uppsala 2003.

[8] Ö. Akyazı, M. Th., Karadeniz Technical University, Trabzon, 2006.

[9] I. Ivanova, O. Agren, H. Bernhoff, M. Leijen, Fourth European Wave Energy Conference, Ireland 2003, p. 345 . 